\title{
Identification and genomic analysis of two novel duck-origin GPV-related parvovirus in China
}

\author{
Guozhi Bian ${ }^{1,2+}$, Haibin Ma ${ }^{2 \dagger}$, Mengping Luo ${ }^{2}$, Fengping Gong ${ }^{2}$, Bo Li ${ }^{2}$ Guiping Wang ${ }^{2}$, Mudassar Mohiuddin², \\ Ming Liao ${ }^{1}$ and Jianfeng Yuan ${ }^{2^{*}}$ (D)
}

\begin{abstract}
Background: Since early 2015, mule duck and Cherry Valley duck flocks have been suffering from short beak and dwarfism syndrome. This widely spreading infectious disease is characterized by growth retardation, smaller beak and tarsus with high morbidity and low mortality rate. For better understanding, we identified and characterized virus isolates named AH and GD from diseased Cherry Valley duck and mule duck flocks and investigated the damage caused by novel parvovirus-related virus (NGPV) to tissues and organs, including kidney, brain, pancreas, liver, spleen, bursa of fabricius and myocardial tissues.

Results: $\mathrm{AH}$ and GD isolates shared high nucleotide identity with goose parvovirus (GPV). Alignment studies of $\mathrm{AH}$ and GD isolates showed 94.5-99.2\% identity with novel parvovirus-related virus (NGPV), 98.7-91.5\% identity with GPV and 79.9-83.7\% with muscovy duck parvovirus (MDPV). Compared with other NGPV, classical GPV and MDPV sequences, a four 14-nucleotide-pair insertion in GD isolate was found in left open reading frame (ORF) (87-100 nt and 350-363 nt) and in right ORF (4847-4861 nt and 5122-5135 nt). However, in AH isolate, a five 14-nucleotidepair deletions similar to other NGPV were found. The complete genome sequence comparison of eleven NGPV isolates from mule ducks and cherry valley ducks revealed no remarkable difference between them. Notably, the myocardium and bursa of fabricius of both disease and healthy animals are perfectly normal while other tissues have inflammatory cells exudation.
\end{abstract}

Conclusions: The AH and GD strains are novel parvovirus-related virus that isolates from mule ducks or cherry valley ducks which DNA sequence has no remarkable difference. The histopathology of tissues and organs such as kidney, brain etc. revealed non-significant changes in experimental and control animals. Overall, this study has contributed better understanding of molecular biology of NGPV strains and will help to develop the candidate strain for vaccine preparation to get better protection against these viral infections.

Keywords: Novel parvovirus-related virus, Phylogenetic analysis, Mule duck, Cherry valley duck

\section{Background}

Muscovy duck parvovirus (MDPV) and Goose parvovirus (GPV) are members of the family Parvoviridae [1, 2]. GPV are etiological agents for Derzsy's disease and results in huge economic losses to the duck industry [3]. The mortality rate in goslings during first four weeks of

\footnotetext{
* Correspondence: peteryuanfeng@163.com

${ }^{\dagger}$ Guozhi Bian and Haibin Ma are contributed equally to this work

${ }^{2}$ Guangdong Haid Institute of Animal Husbandry \& Veterinary, Guangzhou

511400, China

Full list of author information is available at the end of the article
}

life ranges from 70 to $100 \%$ [4]. The disease in infected animals is characterized by lethargy, stunting, anorexia, locomotor dysfunction, watery diarrhea and death within 3 to 5 days after disease onset $[1,5,6]$. MDPV infection mainly affects three-week-old Muscovy ducklings and is characterized by signs almost similar to GPV. The complete nucleotide sequence of the two parvoviruses shares 79.7 to $85.0 \%$ homology.

Waterfowl parvoviruses, including MDPV and GPV, contain a linear, single-stranded DNA genome (approx.

(c) The Author(s). 2019 Open Access This article is distributed under the terms of the Creative Commons Attribution 4.0 International License (http://creativecommons.org/licenses/by/4.0/), which permits unrestricted use, distribution, and reproduction in any medium, provided you give appropriate credit to the original author(s) and the source, provide a link to the Creative Commons license, and indicate if changes were made. The Creative Commons Public Domain Dedication waiver (http://creativecommons.org/publicdomain/zero/1.0/) applies to the data made available in this article, unless otherwise stated. 
Table 1 Primers used to amplify the complete genome

\begin{tabular}{|c|c|c|c|c|}
\hline Primers & Sequences & Position & Size of PCR products (bp) & Annealing temperature \\
\hline P1-F & CTCATTGGAGGGTTCGTTCG & $1-20$ & 191 & $58^{\circ} \mathrm{C}$ \\
\hline P1-R & GCATGCGCGTGGTCAACCTAACA & 169-191 & & \\
\hline P2-F & CAAACGGGGAGGGCAAAATAAGA & $186-208$ & 1345 & $60^{\circ} \mathrm{C}$ \\
\hline P2-R & GTGGTCGCAGGTCCGTAGAGC & $1511-1531$ & & \\
\hline P3-F & GGGTGAAGAGAGAGTTCAACAA & $1474-1497$ & 1137 & $52^{\circ} \mathrm{C}$ \\
\hline P3-R & CGTTACCAGGCCCAAGATAC & $2591-2610$ & & \\
\hline P4-F & GGCATTTGAAAGCTGGAGCC & $2473-2492$ & 922 & $60^{\circ} \mathrm{C}$ \\
\hline P4-R & GTCTTCGTCTGATCCTGCGT & 3375-3395 & & \\
\hline P5-F & TTGCGATTCCCAATGGATG & 3089-3107 & 1171 & $58^{\circ} \mathrm{C}$ \\
\hline P5-R & CCCAAATAGGTCCCTGTAGATA & $4239-4260$ & & \\
\hline P6-F & CTACAACCCGGACCTGTGTC & 3948-3967 & 921 & $60^{\circ} \mathrm{C}$ \\
\hline P6-R & GCATGCGCGTGGTCAACCTAACA & $4846-4868$ & & \\
\hline
\end{tabular}

Table 2 Parvovirus complete genome sequences used in this study

\begin{tabular}{|c|c|c|c|c|c|c|}
\hline Virus & Strain & Location & Host & Genome size & Genbank accession no. & Year \\
\hline Classical GPV & B & Hungary & goose & 5106 & U25749 & 1995 \\
\hline Classical GPV & $E$ & China & goose & 5125 & KC184133 & 2013 \\
\hline Classical GPV & GDaGPV & China & goose & 5106 & HQ891825 & 1978 \\
\hline Classical GPV & $\mathrm{SH}$ & China & goose & 5106 & JF333590 & 2009 \\
\hline Classical GPV & SYG61v & China & goose & 5102 & KC996729 & 1961 \\
\hline Classical GPV & VG32/1 & Taiwan & goose & 5104 & EU583392 & 2008 \\
\hline Classical GPV & Y & China & goose & 5106 & KC178571 & 2011 \\
\hline Classical GPV & YZ99-6 & China & goose & 5046 & KC996730 & 1999 \\
\hline Classical GPV & $\mathrm{LH}$ & China & goose & 5047 & KM272560 & 2012 \\
\hline Classical GPV & 06-0329 & Taiwan & goose & 5054 & EU583391 & 2006 \\
\hline Classical GPV & $82-0321 \mathrm{~V}$ & Taiwan & goose & 4980 & EU582289 & 2008 \\
\hline MDPV & $P$ & China & Muscovy duck & 5123 & KU844281 & 1988 \\
\hline MDPV & GX5 & China & Muscovy duck & 5132 & KM093740 & 2011 \\
\hline MDPV & FZ91-30 & China & Muscovy duck & 5131 & KT865605 & 1991 \\
\hline MDPV & SAAS-SHNH & China & Muscovy duck & 5061 & KC171936 & 2013 \\
\hline NGPV & SDLC01 & China & Cherry Valley duck & 5006 & KT343252 & 2015 \\
\hline NGPV & QH15 & China & Cherry Valley duck & 5048 & KT751090 & 2015 \\
\hline NGPV & SDLY1512 & China & Cherry Valley duck & 5054 & MF441221 & 2015 \\
\hline NGPV & SDLY1604 & China & Cherry Valley duck & 5054 & MF441223 & 2016 \\
\hline NGPV & SDLY1605 & China & Cherry Valley duck & 5054 & MF441224 & 2016 \\
\hline NGPV & AH1606 & China & Cherry Valley duck & 5054 & MF441225 & 2016 \\
\hline NGPV & JS1603 & China & Cherry Valley duck & 5055 & MF441226 & 2016 \\
\hline NGPV & $\mathrm{AH}$ & China & Cherry Valley duck & 5053 & MH444513 & 2015 \\
\hline NGPV & $\mathrm{GD}$ & China & mule duck & 5106 & $\mathrm{MH} 444514$ & 2016 \\
\hline NGPV & M15 & China & mule duck & 5030 & KU844283 & 2015 \\
\hline NGPV & MDE & China & mule duck & 5106 & MF438102 & 2015 \\
\hline
\end{tabular}


5.0-5.1 kb in length) [7]. At both ends of GPV and MDPV genome, there are two inverted terminal repeats (ITR) forming a hairpin structure which contains a stem region and a bubble region having length 456 and $442 \mathrm{nu}-$ cleotides for MDPV and GPV respectively [8,9]. There are two open reading frames (ORFs) in waterfowl parvoviruses $[10,11]$. The left ORF encodes non-structural (NS) proteins NS1 and NS2 and right ORF encodes structural proteins namely VP1, VP2 and VP3 [12, 13].

During 1970s, Short beak and dwarfism syndrome (SBDS) was first reported in France in mule ducks, caused by a novel parvovirus-related virus (NGPV) [14, 15]. Since March 2015, there are numerous SBDS outbreaks in mule duck and Cherry Valley duck flocks in various regions of China $[16,17]$. The morbidity rate of NGPV was found to be $10-30 \%$ while mortality rate was about $2 \%$ [18]. The ducks infected with NGPV, showed clinical symptoms like swollen tongue, shorter tibia and stunted growth [14]. In this way, the disease causes huge economic losses to duck industry by reduction in weight and size of animals. However, the adult ducks were found resistant to SBDS disease [14].

In order to have better understanding of SBDS disease, we characterized two NGPV namely $\mathrm{AH}$ and GD isolates, obtained from mule duck and Cherry Valley duck flocks in Anhui and Guangdong province, China. For detailed analysis, the complete genome of these isolates was sequencedand homology studies and phylogenetic comparison was carried out. The nucleotide sequences of the $\mathrm{AH}$ and GD genome and ITR were aligned for comparison with other GPV/ MDPV/NGPV strains. The amino acid sequences of non-structural and structural proteins were also subjected to phylogenetic and homology analysis. The histopathological features were also studied in experimental and control groups.

\section{Methods}

\section{Sample collection}

In 2014-2015, two mule duck and Cherry Valley duck flocks located in Guangdong and Anhui province, China were found to be suffering from SBDS disease. Liver and spleen samples were collected from diseased birds and processed for viral isolation.

\section{Virus isolation}

The AH and GD strains of variant GPV were isolated from mule duck and Cherry Valley duck flocks with typical signs of SBDS. Liver and spleen tissues were grinded and homogenized in physiological saline, freeze-thawed three times and centrifuged at $10,000 \times \mathrm{g}$ for $15 \mathrm{~min}$ at $4{ }^{\circ} \mathrm{C}$. The supernatants were subjected to filtration using $0.22 \mu \mathrm{m}$ sterile filters to remove contaminants and inoculated into chorioallantoic cavity of 10-day-old duck embryonated eggs $(200 \mu \mathrm{l} / \mathrm{egg})$. The allantoic fluid was harvested 5 days after inoculation and stored at $-80^{\circ} \mathrm{C}$ for further testing.

\section{DNA extraction}

The allantoic fulid of $\mathrm{AH}$ and GD isolates was centrifuged at $5000 \mathrm{xg}$ for $10 \mathrm{~min}$ to remove cellular debris and proceeded for DNA extraction using AxyPrep DNA Extraction Kit (ANYGEN). The stock DNA was dissolved in TE buffer for future use.

\section{Amplification of $\mathrm{AH}$ and GD complete genome}

To amplify the complete genome of GD and AH isolates, six primer pairs were designed, based on the conserved regions in the genome sequence of NGPV (Table 1). The polymerase chain reaction conditions were as follows: $95^{\circ} \mathrm{C}$ for $5 \mathrm{~min}$, followed by 35 cycles of denaturation $\left(95^{\circ} \mathrm{C}\right.$ for $\left.30 \mathrm{~s}\right)$, annealing $\left(52-60^{\circ} \mathrm{C}\right.$ for $30 \mathrm{~s}$ ), extension $\left(72{ }^{\circ} \mathrm{Cfor} 2 \mathrm{~min}\right.$ ) and a final extension at $72{ }^{\circ} \mathrm{C}$ for $10 \mathrm{~min}$. The complete genome sequence was obtained by assembling all six DNA fragments.

\section{Cloning and sequencing}

The amplified PCR products were purified using gel extraction kit (AXYGEN), and all fragments were cloned into pMD18-T vector (TaKaRa). The plasmids were sequenced by Sangon Tech (Sangon Biotech, shanghai, China). For ensuring accuracy of genomic sequences, triplicate clones of fragments were sequenced.

\section{Sequence analysis}

Using BLAST sequence alignment, all six fragments were assembled to form a full-length complete genome. The sequence alignment and homology studies for whole-genome, NS (non-structural proteins) and VP (structural proteins) of GD and AH isolates was done by comparison with already reported sequences in the

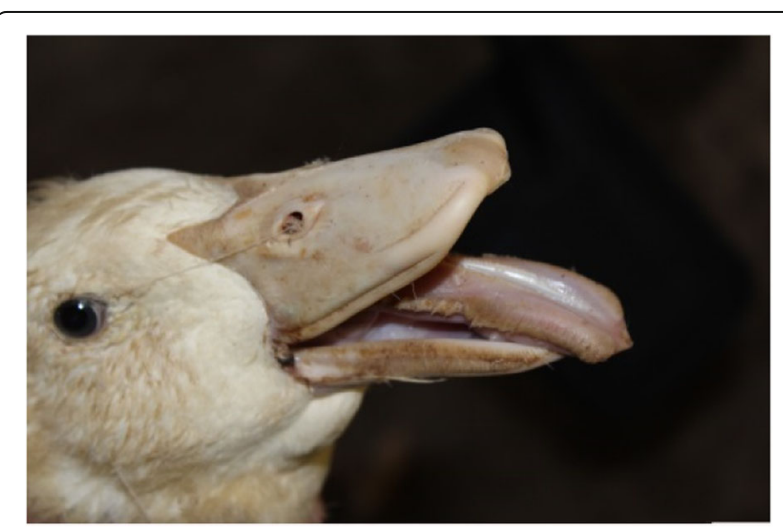

Fig. 1 Clinical signs in infected ducklings. The main signs and symptoms in AH or GD-infected ducklings were retarded in growth 
Genbank using MegAlign and MEGA 5.0 software programs [19] (Table 2).

\section{Histopathological examination}

Histopathological investigations were carried out in the diseased flocks by comparison with the healthy (Control) animals. At 14 days post infection (DPI), the animals were euthanized and necropsied. Intravenous anesthesia of high concentrations of pentobarbital sodium $(150 \mathrm{mg} / \mathrm{kg})$ was used in this study. Samples of kidney, brain, pancreas, liver, spleen, bursa of fabricius and myocardial tissues were fixed with $10 \%$ formalin; all the tissues were dehydrated, and immersed in transparent wax, cut into slices and stained with $\mathrm{H}$ \& $E$ dye. All of the animal protocols were performed in accordance with the 'Guidelines for Experimental Animals' of Ministry of Science and Technology (Beijing, China).

\section{Results}

\section{Viral isolation}

Two NGPV strains (GD and AH) were isolated from NGPV-positive mule duck and Cherry Valley duck samples respectively. These isolates were not able to cause

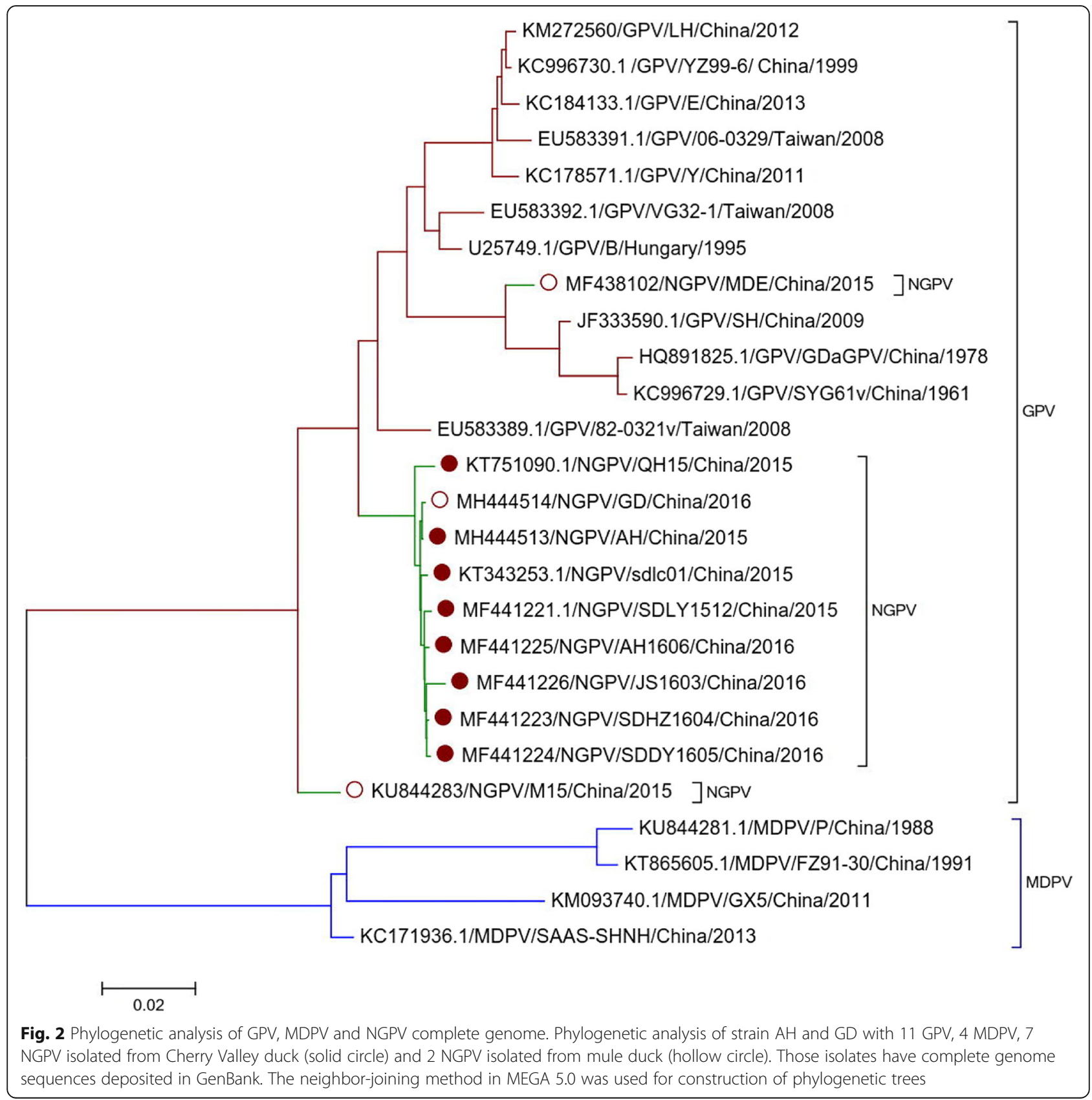


death in duck embryonic eggs 5 days post infection (dpi). The main signs and symptoms in AH or GD-infected ducklings were retarded in growth with low mortality rate (Fig. 1).

\section{Complete genome sequence analysis}

The complete genome sequence of mule duck isolate "GD" and Cherry Valley duck isolate "AH" was 5106 bp and $5053 \mathrm{bp}$ respectively. The sequences were submitted to GenBank and their accession numbers are indicated in Table 2. The NGPV genome contained two identical inverted terminal repeats (ITRs) and two open reading frames (ORFs). The length of ITRs of $\mathrm{AH}$ and GD genome was 379 and 407 nucleotides (nt) respectively.

Phylogenetic analysis of NGPV, GPV and MDPV sequences revealed that all NGPV isolates have more similarity with GPV than MDPV (Fig. 2). Homology among NGPV isolates ranges from 93.4 to $99.9 \%$ at whole genome level. All NGPV isolates share 89.7-96.7\% identity with classical GPV and 79.6-83.9\% identity with MDPV. These results revealed that there is no significant difference among NGPV isolated either from mule duck or Cherry Valley duck and also the NGPV isolates are more closely related to GPV virus. Sequence alignment of NGPV with classical GPV and MDPV using MEGA 5.0 software revealed three 14-nucleotide sequences deletion in most of NGPV isolates (Fig. 3). A putative recombination was also observed in GD strain between $87 \mathrm{nt}-$ 100 nt (Fig. 3).

\section{Phylogenetic analysis of NS genes}

In order to understand the genetic diversity of Non-structural proteins (NS) in NGPV, GPV and MDPV isolates, phylogenetic tree was constructed and homology analysis was also carried out (Fig. 4). Through sequence alignment, it was found that the length of NS proteins of all NGPV, GPV and MDPV sequences is $1881 \mathrm{nt}$, and they encode 626 amino acids. Through comparison of NS gene, both NGPV isolates (AH and GD) have more similarly with GPV than MDPV, which is similar to complete genome sequence findings.

Homology of NS proteins among NGPV isolates ranged between $93.7-100 \%$ at gene level and $95.4-100 \%$ at amino acid level. However, they share 93.4-97.9\% identity with classical GPV and 81.0-82.4\% identity with MDPV. At amino acid level, all NGPV isolates shared 96.3-99.5\% identity with classical GPV and 89.0-90.1\% identity with MDPV. As compared to classical GPV and MDPV, there are twelve synchronous specific mutations in NS amino acids (Table 3).

\section{Phylogenetic analysis of VP genes}

The genetic diversity of VP gene (Capsid protein gene) was also studied by phylogeny and homology analysis (Fig. 5). Through sequence alignment, it was found that the length of all VP genes of NGPV, GPV and MDPV is $2199 \mathrm{nt}$ and they encode 732 amino acids. The comparison of VP gene also showed more similarity of NGPV (AH and GD) sequences with GPV than MDPV sequences, which is similar to the

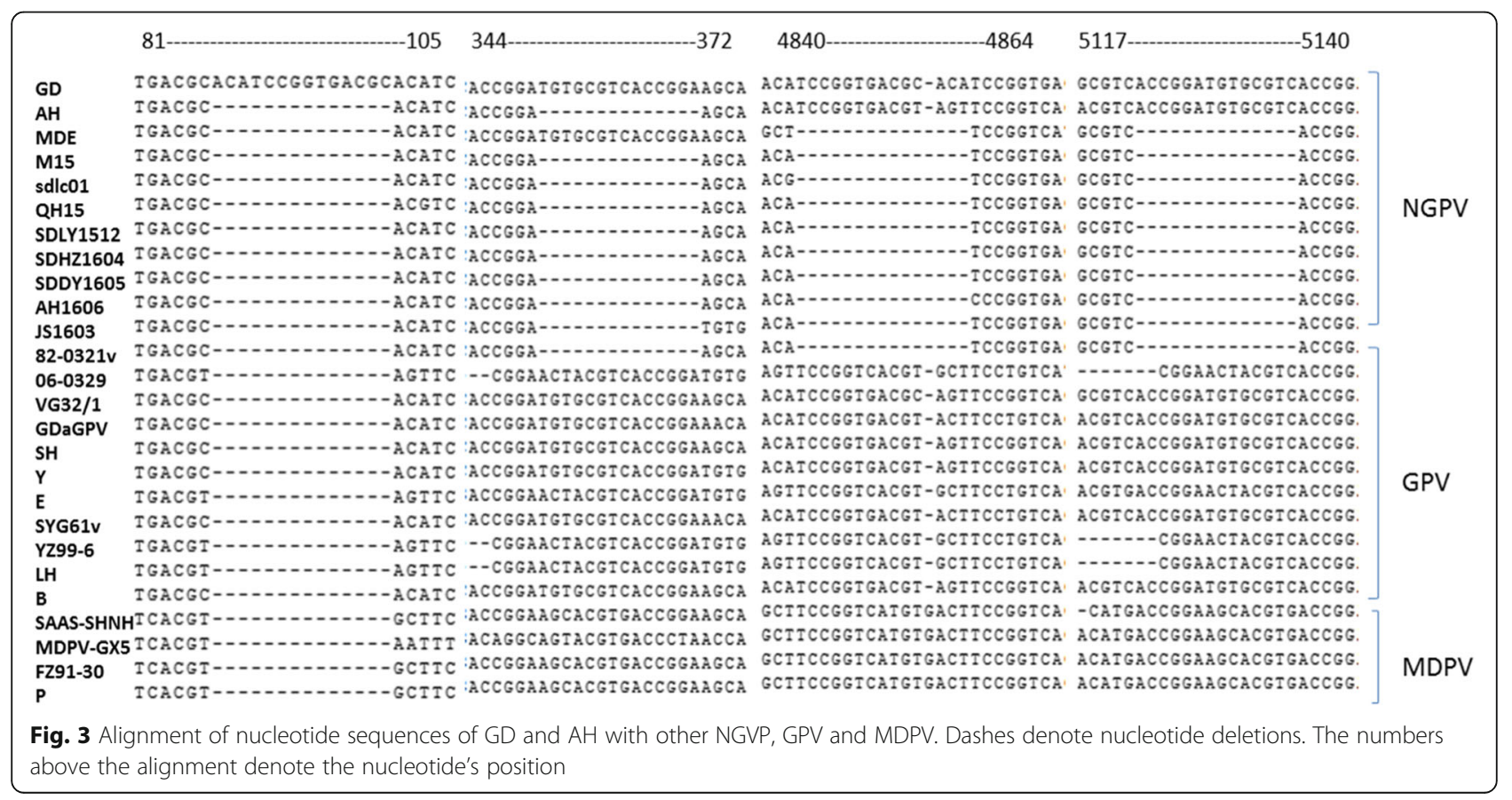




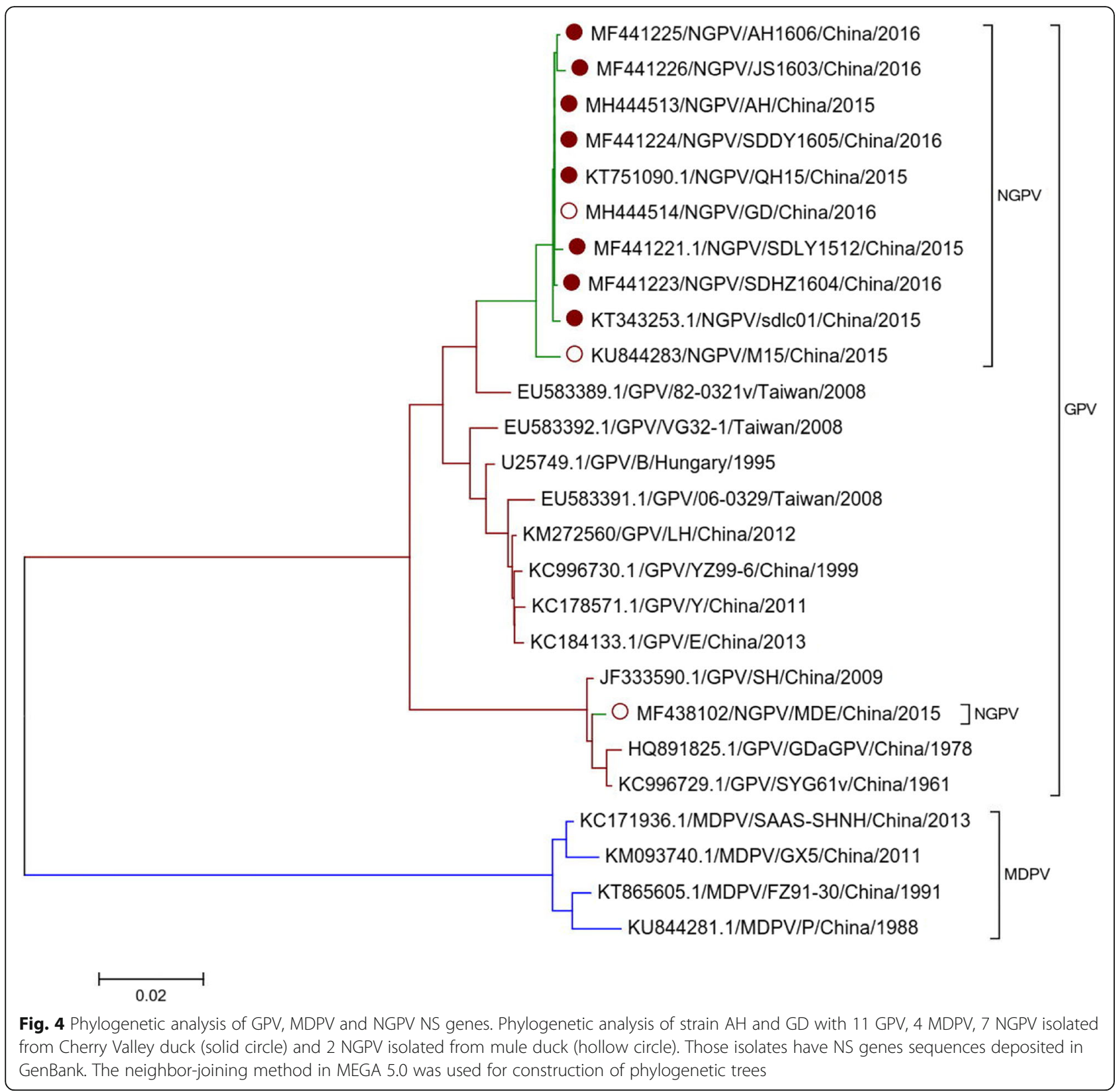

findings of complete genome sequence and NS gene analysis.

Homology among NGPV isolates ranged between 94.0$100 \%$ at VP gene level and $96.9-100 \%$ at amino acid level. The VP gene of NGPV isolates has $90.9-97.5 \%$ identity

Table 3 Amino acid mutations in replication

\begin{tabular}{llllllllllllll}
\hline Virus & \multicolumn{11}{l}{ Sites in replication protein } \\
\cline { 2 - 13 } & 50 & 131 & 140 & 350 & 468 & 498 & 553 & 555 & 573 & 594 & 605 & 617 \\
\hline NGPV & T & R & S & V & I & R & K & T & Q & Y & T & A \\
GPV & I & K & A & A & V & E & R & N & E & D & K & V \\
MDPV & I & K & A & A & V & E & R & D & E & N & N & V \\
\hline
\end{tabular}

with classical GPV and 80.9-91.5\% identity with MDPV. At VP amino acid level, NGPV isolates shared 95.1-98.2\% identity with classical GPV, and 88.0-92.6\% identity with MDPV. As compared to classical GPV and MDPV, there are eight synchronous specific mutations in $\mathrm{VP}$ amino acids (Table 4).

\section{Histopathological examination}

To find out the damage caused by NGPV to tissues and organs, including kidney, brain, pancreas, liver, spleen, bursa of fabricius and myocardial tissues, histopathological investigations were carried out (Fig. 6). In both experimental and control animals, myocardium and bursa of 


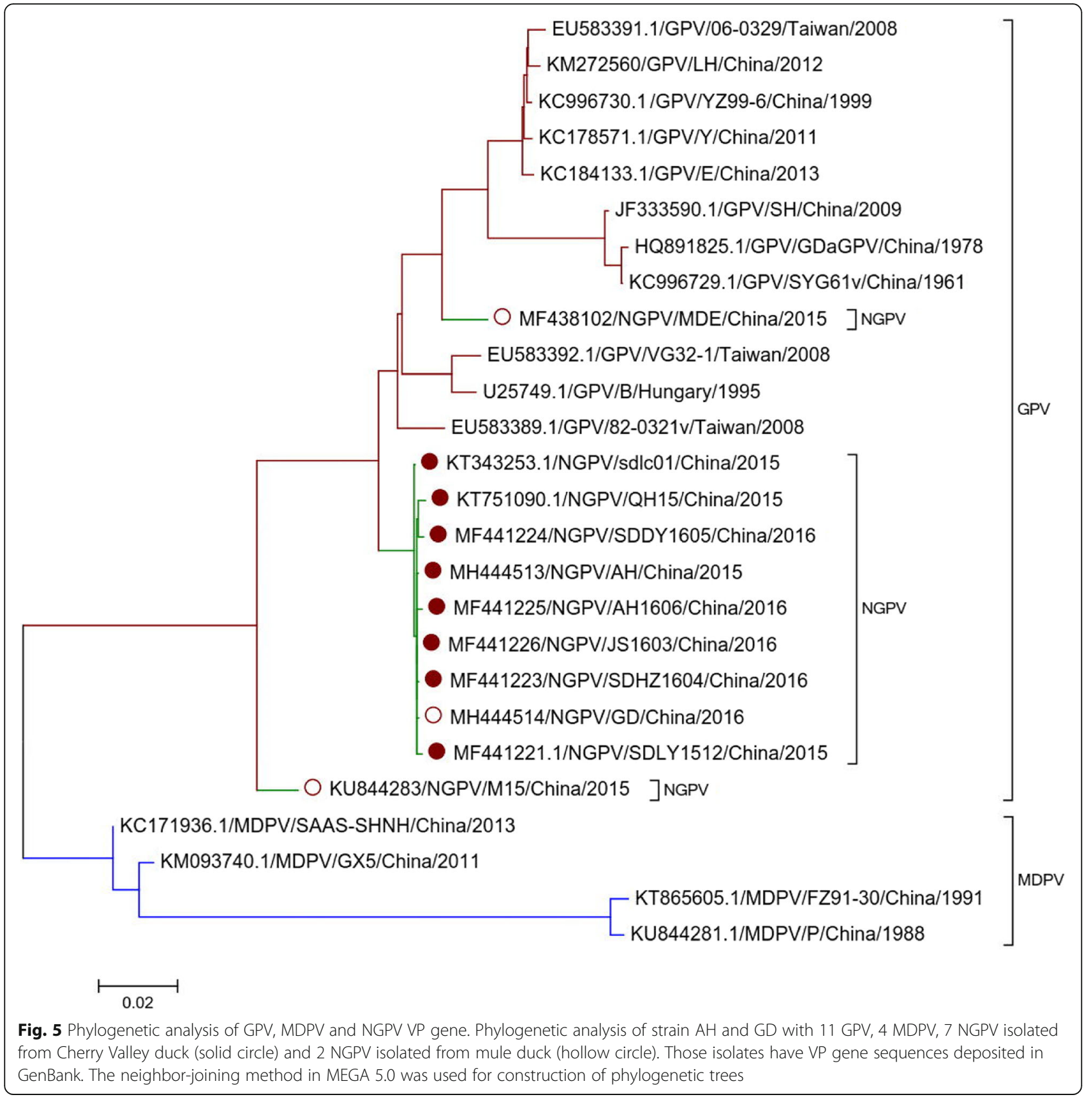

from Cherry Valley duck (solid circle) and 2 NGPV isolated from mule duck (hollow circle). Those isolates have VP gene sequences deposited in GenBank. The neighbor-joining method in MEGA 5.0 was used for construction of phylogenetic trees

Table 4 Simultaneous amino acid mutations in capsid protein

\begin{tabular}{lllllllll}
\hline virus & \multicolumn{7}{l}{ Sites in capsid protein } \\
\cline { 2 - 9 } & 89 & 114 & 116 & 142 & 180 & 450 & 498 & 660 \\
\hline NGPV & L & H & H & E & V & N & N & N \\
GPV & Q & D & Q/R & D & A & S & S & H \\
MDPV & Q & D & T & D & G & N/G & N/S & N \\
\hline
\end{tabular}

fabricius are perfectly normal and the other tissues have inflammatory cells exudation. The results suggested that NGPV has no significant influence on these tissues and organs.

\section{Discussion}

In this study, we studied the complete genome sequence of $\mathrm{AH}$ and GD, isolated from mule duck and Cherry Valley duck flocks reported with SBDS from Anhui and Guangdong province, China. SBDS in ducks was first reported in France in 1970s [14], followed by outbreaks in Taiwan (1989), Poland (1995) [2, 14], Hungary (2009) 


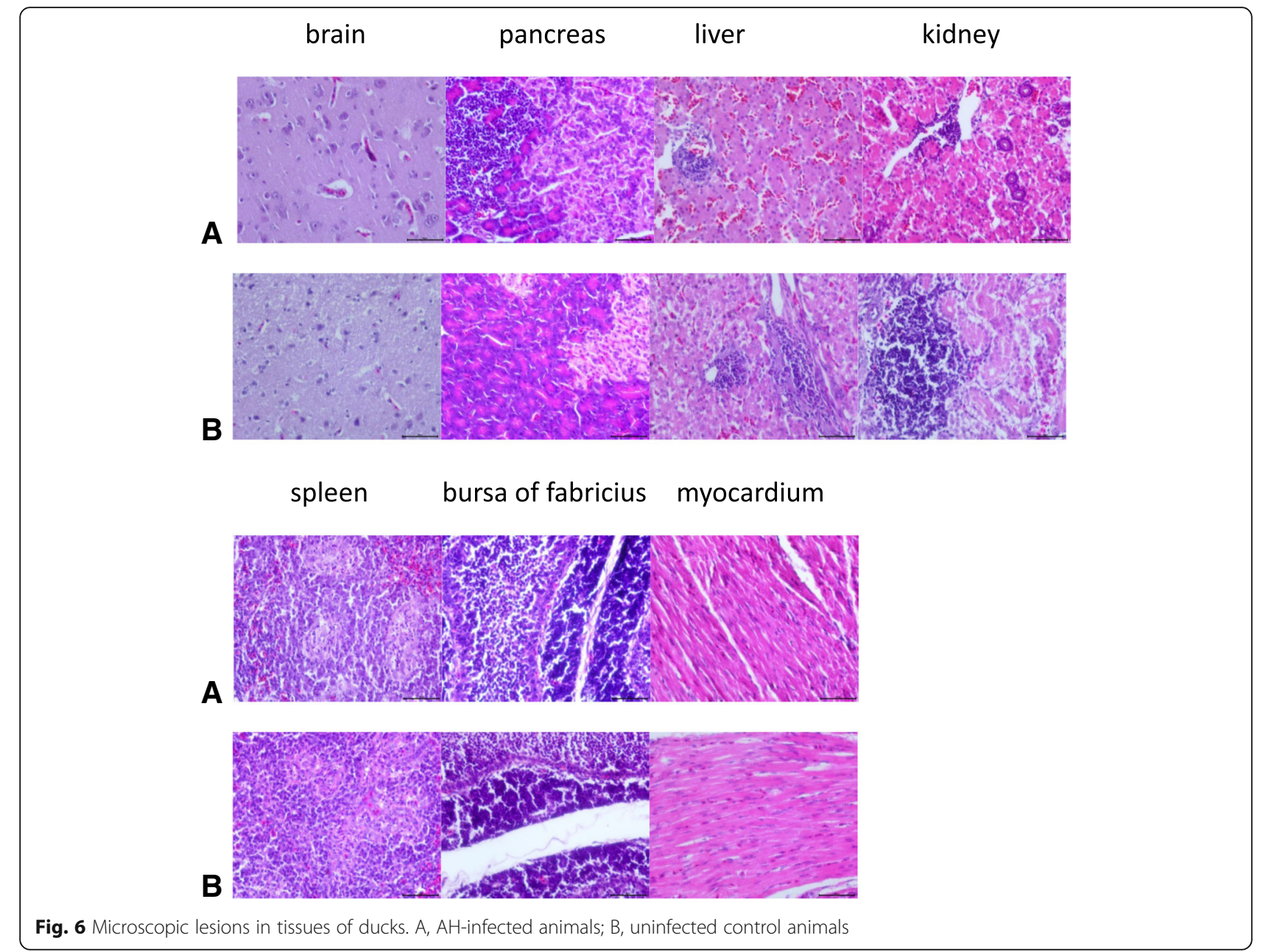

[14] and mainland China (2014) [20]. Although the genome sequences of NGPV, GPV and MDPV strains have been reported previously, but this is the first study, which reported variations among various parvovirus duck strains on the basis of phylogeny and homology analysis $[4,14,17,21]$. The sequence analysis indicated that all NGPV isolates have more homology among them as compared to classical GPV and MDPV. Several studies reported SBDS in ducks maybe caused by novel-MDPV is also reported, but the whole genome sequence analysis has shown that GPV clade also exists in this paper, which the rusults might be due to coinfection with NGPV and MDPV strains [22].

The complete genome sequence of AH and GD strains contain $5053 \mathrm{nt}$ and $5106 \mathrm{nt}$ respectively and they shared 93.4-99.9\% identity with other NGPV, 89.7-96.7\% identity with classical GPV and $79.6-83.9 \%$ identity with MDPV strains. The length of ITRs of AH and GD is 379 and $407 \mathrm{nt}$ respectively. Through sequence alignment, it was found that the length of NS protein of all NGPV, GPV and MDPV strains is $1881 \mathrm{nt}$ encoding 626 amino acids and the length of VP gene of all NGPV, GPV and
MDPV strains is $2199 \mathrm{nt}$ which encodes 732 amino acids. When comparison was carried out between mule duck isolates including GD and Cherry Valley duck isolates including $\mathrm{AH}$, it was found that NGPV isolated from mule duck and those isolated from Cherry Valley duck have no significant differences among them.

VP protein plays an important role in the stimulation of protective response in the body against the virus as it contains viral antigenic sites [23-25]. Interestingly VP protein of NGPV and classical GPV shares 90.9 to $97.5 \%$ homology, therefore it is very likely that vaccine against GPV is effective against NGPV. However, in this case, it's protective efficacy may slightly decrease. Further studies are required to explore the effectiveness of currently available vaccines against NGPV and to develop a new vaccine for NGPV. It will be a difficult task as virus titer is low in duck embryo and large scale culturing of NGPV would be challenging.

The complete genome sequence analysis also showed that most of NGPV isolates have several 14-nucleotide sequence deletions not found in classical GPV and MDPV sequences. It was also noticed and reported for 
the first time that the 14-nucleotide sequences deletion is identical to each other and the front and back of deleted position also have a same 14-nucleotide sequences. These results lead us to suspect that the 14-nucleotide sequences deletion play a major role in migration of host, if sequencing mistakes are excluded. The SimPlot analysis of GD strain with other strains revealed no clear indication of increase in genome at at $87 \mathrm{nt}-100 \mathrm{nt}$. However, as it is too short (14 nt), therefore it might be possible that SimPlot software could not able to use analysis recombination.

The histopathological examination revealed no remarkable difference in kidney, brain, pancreas, liver, spleen, bursa of fabricius, myocardium tissues between experimental group and control group. These findings suggested that NGPV causes non-significant pathological changes in these organs and tissues, which might be the reason of low mortality in infected animals $(2 \%)$.

In conclusion, the novel parvovirus-related virus is responsible for SBDS disease outbreaks in eastern China since 2014 [21, 26]. The low mortality and smaller beak is the major difference between NGPV and GPV infected animals. NGPV is hard to culture in duck embryos and DEF (duck embryos fibroblast). Since classical GPV does not infect mule duck and Cherry Valley ducks, therefore NGPV is not completely adapted to cause severe disease in mule duck and Cherry Valley duck which might be the reason for low mortality caused by these strains. The NGPV also has little pathological impact on kidney, brain and other organs and tissues. However, further studies are required to evaluate the protective efficacy of classical GPV vaccine against SBDS and to develop a new vaccine for this disease.

\section{Conclusions}

$\mathrm{AH}$ and GD strains isolated from mule duck and Cherry Valley duck flocks are novel parvovirus-related virus. The comparison of complete genome sequence of eleven NGPV isolates from mule ducks and cherry valley ducks found no remarkable difference between them. Through histopathological examination, it was found that both experimental and control groups have perfectly normal myocardium and bursa of fabricius while other tissues have inflammatory cells exudation. The results suggested that NGPV has no significant influence on the tissues and organs. This study has contributed better understanding of molecular biology of NGPV strains and will help to develop the candidate strain for vaccine preparation in future.

\section{Abbreviations}

GPV: Goose parvovirus; ITR: Inverted terminal repeats; Kb: Kilobase; MDPV: Muscovy duck parvovirus; NGPV: Novel parvovirus-related virus; NS: Non-structural proteins; Nt: Nucleotides; ORF: Open reading frame; SBDS: Short beak and dwarfism syndrome; VP: Capsid protein gene

\section{Acknowledgements}

Not applicable.

\section{Funding}

This was supported by National Program on Key Reasearch Project of China (No. 2017YFD0500800), Guangdong Provincial Scientific and Technological Planning Project (No. 201704020083), Guangdong Provincial special Project for Science and Technology development

(2016B020234006,2017B090904029), Guangdong Province Technology development and industrialization (2015B020203006).

\section{Availability of data and materials}

The genomic sequence has been deposited in GenBank with accession number MH444513 and MH444514. Other data supporting the findings is contained within the manuscript.

\section{Authors' contributions}

GB and HM have contributed equally to this paper. GB and HM designed and wrote the paper. $M L, F G, B L, G W$ and $M M$ performed the experiments. $\mathrm{ML}$ and $J Y$ checked and revised the manuscript. All authors have read and approved the final version of the manuscript and ensure this is the case.

\section{Ethics approval and consent to participate}

All of the animal protocols were performed in accordance with the 'Guidelines for Experimental Animals' of Ministry of Science and Technology (Beijing, China) and the study was approved by the Research Ethics Committee of the Institute of Veterinary Medicine College of South China Agricultural University. No specific permits were required for these locations and activities.

\section{Consent for publication}

Not applicable.

\section{Competing interests}

The authors declare that they have no competing interests.

\section{Publisher's Note}

Springer Nature remains neutral with regard to jurisdictional claims in published maps and institutional affiliations.

\section{Author details}

${ }^{1}$ Veterinary Medicine College of South China Agricultural University, Guangzhou 510642, China. ${ }^{2}$ Guangdong Haid Institute of Animal Husbandry \& Veterinary, Guangzhou 511400, China.

Received: 29 October 2018 Accepted: 3 March 2019

Published online: 12 March 2019

\section{References}

1. Glávits R, Zolnai A, Szabó E, Ivanics E, Zarka P, Mató T, Palya V. Comparative pathological studies on domestic geese (Anser anser domestica) and Muscovy ducks (Cairina moschata) experimentally infected with parvovirus strains of goose and Muscovy duck origin. Acta Vet Hung. 2005;53(1):73.

2. Woźniakowski G, Kozdruń W, Samoreksalamonowicz E. Genetic variance of Derzsy's disease strains isolated in Poland. Journal of Molecular \& Genetic Medicine An International Journal of Biomedical Research. 2009;3(2):210.

3. Derzsy D, Kisary J. Viral disease of goslings: World Veterinary Congress; 1975.

4. Yu K, Ma X, Sheng Z, Qi L, Liu C, Dan W, Bing H, Feng L, Song M. Identification of goose-origin parvovirus as a cause of newly emerging beak atrophy and dwarfism syndrome in ducklings. J Clin Microbiol. 2016;54(8): 1999.

5. Kisary J: Some growth characteristics of goose parvovirus strain "B". Acta Vet Acad Sci Hung 1974, 24(3):329.

6. Takehara K, Hyakutake K, Imamura T, Mutoh Kl, Yoshimura M. Isolation, identification, and plaque titration of parvovirus from Muscovy ducks in Japan. Avian Dis. 1994;38(4):810.

7. Le GRG, Jestin V. Biochemical and genomic characterization of Muscovy duck parvovirus. Arch Virol. 1994;139(1-2):121-31.

8. Wang J, Duan J, Meng X, Gong J, Jiang Z, Zhu G. Cloning of the genome of a goose parvovirus vaccine strain SYG61V and rescue of infectious virions 
from recombinant plasmid in embryonated goose eggs. J Virol Methods. 2014;200(10):41.

9. Wang J, Huang Y, Zhou M, Hardwidge PR, Zhu G. Construction and sequencing of an infectious clone of the goose embryo-adapted Muscovy duck parvovirus vaccine strain FZ91-30. Virol J. 2016;13(1):1-8.

10. Ji J, Xie QM, Chen CY, Bai SW, Zou LS, Zuo KJ, Cao YC, Xue CY, Ma JY, Bi YZ. Molecular detection of Muscovy duck parvovirus by loop-mediated isothermal amplification assay. Poult Sci. 2010;89(3):477-83.

11. Shen H, Zhang W, Wang H, Zhou Y, Shao S. Identification of recombination between Muscovy duck parvovirus and goose parvovirus structural protein genes. Arch Virol. 2015;160(10):1-5.

12. Zádori Z, Stefancsik R, Rauch T, Kisary J. Analysis of the complete nucleotide sequences of goose and Muscovy duck Pervoviruses indicates common ancestral origin with adeno-associated virus 2. Virology. 1995;212(2):562-73.

13. Poonia B, Dunn PA, Lu H, Jarosinski KW, Schat KA. Isolation and molecular characterization of a new Muscovy duck parvovirus from Muscovy ducks in the USA. Avian Pathology. 2006;35(6):435-41.

14. Palya V, Zolnai A, Benyeda Z, Kovács E, Kardi V, Mató T. Short beak and dwarfism syndrome of mule duck is caused by a distinct lineage of goose parvovirus. Avian Pathology. 2009;38(2):175.

15. Villate D, Caldier P. Manuel pratique des maladies des palmipedes; 1989

16. Chen H, Dou Y, Tang Y, Zhang Z, Zheng X, Niu X, Yang J, Yu X, Diao Y. Isolation and genomic characterization of a duck-origin GPV-related parvovirus from Cherry Valley ducklings in China. PLoS One. 2015;10(10): e0140284.

17. Li P, Lin S, Zhang R, Chen J, Sun D, Lan J, Song S, Xie Z, Jiang S. Isolation and characterization of novel goose parvovirus-related virus reveal the evolution of waterfowl parvovirus. Transboundary \& Emerging Diseases. 2017;65(2).

18. Fan W, Sun Z, Shen T, Xu D, Huang K, Zhou J, Song S, Yan L. Analysis of evolutionary processes of species jump in waterfowl parvovirus. Front Microbiol. 2017;8:e1003537.

19. Tamura K. MEGA5: molecular evolutionary genetics analysis version 6.0. Molecular Biology \& Evolution. 2013;30(12):2725-9.

20. Chen S, Wang S, Cheng X, Xiao S, Zhu X, Lin F, Wu N, Wang J, Huang M, Zheng $\mathrm{M}$. Isolation and characterization of a distinct duck-origin goose parvovirus causing an outbreak of duckling short beak and dwarfism syndrome in China. Arch Virol. 2016;161(9):2407-16.

21. Xiao S, Chen S, Cheng X, Lin F, Wang S, Zhu X, Yu B, Huang M, Wang J, Wu $N$. The newly emerging duck-origin goose parvovirus in China exhibits a wide range of pathogenicity to main domesticated waterfowl. Vet Microbiol. 2017;203:252-6.

22. Fu Q, Huang Y, Wan C, Fu G, Qi B, Cheng L, Shi S, Chen H, Liu R, Chen Z. Genomic and pathogenic analysis of a Muscovy duck parvovirus strain causing short beak and dwarfism syndrome without tongue protrusion. Res Vet Sci. 2017;115:393.

23. Berns Kl. Parvovirus replication. Microbiol Rev. 1990;54(3):316-29.

24. Salganik M, Aydemir F, Nam HJ, Mckenna R, Agbandjemckenna M, Muzyczka N. Adeno-associated virus capsid proteins may play a role in transcription and second-Strand synthesis of recombinant genomes. J Virol. 2014;88(2):1071-9.

25. Hueffer K, Parker JSL, Weichert WS, Geisel RE, Sgro JY, Parrish CR. The natural host range shift and subsequent evolution of canine parvovirus resulted from virus-specific binding to the canine transferrin receptor. J Virol. 2003; 77(3):1718-26

26. Ning K, Wang M, Qu S, Lv J, Yang L, Zhang D. Pathogenicity of Pekin duckand goose-origin parvoviruses in Pekin ducklings. Vet Microbiol. 2017;210: $17-23$.

Ready to submit your research? Choose BMC and benefit from:
- fast, convenient online submission
- thorough peer review by experienced researchers in your field
- rapid publication on acceptance
- support for research data, including large and complex data types
- gold Open Access which fosters wider collaboration and increased citations
- maximum visibility for your research: over 100M website views per year
At BMC, research is always in progress.
Learn more biomedcentral.com/submissions

